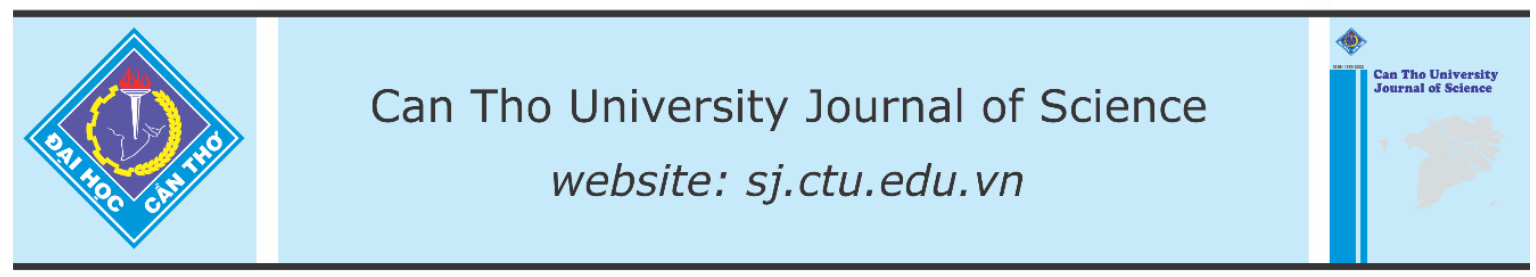

DOI: 10.22144/ctu.jen.2021.018

\title{
Incorporation of amine functional group on surface of hydroxyapatite prepared fromstriped catfish (Pagasianodon hypophthalmus) bone
}

Quoc-Phong Ho ${ }^{1 *}$, Yasuaki Takagi ${ }^{2}$, Lien-Huong Huynh ${ }^{1}$, Nguyen Thanh Tuyen ${ }^{1}$, Minh-Phu Tran ${ }^{3}$, Le Thi Minh Thuy ${ }^{3}$ and Cao Luu Ngoc Hanh ${ }^{1}$

${ }^{1}$ College of Engineering Technology, Can Tho University, Viet Nam

${ }^{2}$ Faculty of Fisheries Sciences, Hokkaido University, Japan

${ }^{3}$ College of Aquaculture and Fisheries, Can Tho University, Viet Nam

*Correspondence: Quoc-Phong Ho (email: hqphong@ctu.edu.vn)

Article info.

Received 22 Feb 2021

Revised 07 Apr 2021

Accepted 04 Jun 2021

\section{Keywords}

(3-aminopropyl)triethoxysilane, biocompatible materials, catfish bone, hydroxyapatite

\section{ABSTRACT}

This study was conducted to incorporate amine functional groups on the surface of hydroxyapatite to enhance its potential application in biomedical materials. Hydroxyapatite particles (HA) were synthesized from striped catfish (Pagasianodon hypophthalmus) bone and surface modified by grafting with (3-aminopropyl)triethoxysilane (APTES). Important factors affected grafting efficiency such as concentration of APTES, water content, reaction temperature and reaction time were studied. X-ray diffraction (XRD), Fourier transform infrared spectroscopy (FTIR) and Scanning electron microscopy (SEM) were used to confirm the grafting reaction on HA surfaces. Grafting efficiency was evaluated based on intensity of characteristic absorption peaks of APT$E S$. The experimental results showed that amine functional groups were successfully introduced on HA surface at optimal condition of $0.2 \mathrm{M}$ APTES, 0.75 wt. $\%$ water content, at $60^{\circ} \mathrm{C}$ and 12 -hour reaction time.

\section{INTRODUCTION}

Hydroxyapatite (HA), a calcium phosphate mineral with a chemical formula of $\mathrm{Ca}_{10}\left(\mathrm{PO}_{4}\right)_{6}(\mathrm{OH})_{2}$ presents in both human bone and teeth. HA crystals is a bioactive ceramic cover 65 to $70 \%$ by weight of the bone and 70 to $80 \mathrm{wt} . \%$ of dentin and enamel. Nano HA is attracting interest as biomaterial for prosthetic applications due to its high biological compatibility, non-toxic, biodegradable as well as its similarity in size, morphology and chemical composition with human hard tissue (Haixin Zhao et al., 2011; Kim, Lee, \& Knowles, 2006; Rivera-Muñoz \& M, 2011; Ylinen, 2006). HA particles of different shapes can be obtained from pure chemicals or natural sources such as catfish bone, fish bone, seashells and egg shells (Sadat-Shojai, Khorasani, DinpanahKhoshdargi, \& Jamshidi, 2013). HA can be combined with polymers such as collagen, to create scaffold materials used in tissue engineering or bone regeneration. However, due to its inorganic occuring, HA is inert and has poor interaction with chemical compounds or bio-components to be introduced in. Therefore, surface modification is essential to overcome this disadvantage. For examples, in order to graft collagen on the surface, $\mathrm{TiO}_{2}, \mathrm{Fe}_{3} \mathrm{O}_{4}, \mathrm{SiO}_{2}$, and $\mathrm{HA}$ need to be modified by 1-ethyl-3-(3-dimethyaminopropyl) carbodiimide (EDC) or N-hydroxysuccinimide (NHS). 
Besides EDC and NHS, (3aminopropyl)triethoxysilane (APTES), 3-amino trimethoxypropyl silane (APTMS) and other agents such as IOTA 5603 and IOTA 5910 are typical agents for anchoring amine groups on the surface of $\mathrm{SiO}_{2}$ through the silanolization of trialkoxysilane $\left(\mathrm{R}^{\prime} \mathrm{O}\right)_{3} \mathrm{Si}-\mathrm{R}-\mathrm{X}$ ( $\mathrm{R}$ is the hydrocarbon $\left(\mathrm{C}_{\mathrm{x}} \mathrm{H}_{\mathrm{y}}\right)$ and $\mathrm{X}$ is the functional group to be created on the surface of materials) were applied to effectively create amine groups on the surface of $\mathrm{SiO}_{2}$ by using silanolization of trialkoxysilane $\left(\mathrm{R}^{\prime} \mathrm{O}\right)_{3} \mathrm{Si}-\mathrm{R}-\mathrm{X}$. Where $\mathrm{R}$ is the hydrocarbon $\left(\mathrm{C}_{\mathrm{x}} \mathrm{H}_{\mathrm{y}}\right)$, and $\mathrm{X}$ is the functional group to be created on the surface of materials. $\mathrm{R}^{\prime}$ is usually methyl or ethyl group and $\mathrm{R}^{\prime} \mathrm{O}$ can be easily hydrolyzed in the presence of water to form silanol that formed covalent bonds with $\mathrm{OH}$ group on inorganic materials (Howarter \& Youngblood, 2006; Pasternack, Rivillon Amy, \& Chabal, 2008).

Due to the presence of hydroxyl groups, an amine functional group can be created on HA surface by using alkoxysilane amine agents such as APTES (Da Silva, Da Silva Filho, Da Fonseca, Arakaki, \&

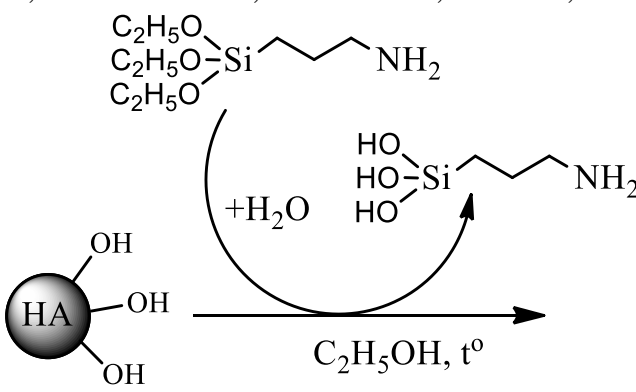

\section{THE EXPERIMENT}

\subsection{Chemicals}

Catfish bone (Pangasius hypophthalmus) was provided from a local fish fillet processing factory. Chemicals such as $\mathrm{NaOH}, \mathrm{H}_{3} \mathrm{PO}_{4}$ and $\mathrm{NH}_{3}$, APTES were supplied by Merck (Vietnam).

\subsection{Preparation of hydroxyapatite from catfish bones}

Fish bone was boiled in water for 4 hours to remove adherent fish meat. Clean bone was dried,
Airoldi, 2006). The mechanism of grafting APTES on HA surface to create amine functional group was shown in Figure 1. In the presence of water, $\mathrm{C}_{2} \mathrm{H}_{5} \mathrm{O}$ - group of APTES was hydrolysed to $\mathrm{NH}_{2}-$ $\left(\mathrm{CH}_{2}\right)_{3} \mathrm{Si}(\mathrm{OH})_{3}$ with silanol groups. The silanol groups then reacted with $\mathrm{OH}^{-}$of $\mathrm{HA}$ to form products such as SP1, SP2, or SP3 (Figure 1), and then amine groups were successfully produced on HA surface. These new introduced amine functional groups allowed the attachment of other bio-molecules to HA surface through nucleophilic reactions, which broadened the applications of HA in drug delivery, scaffold fabrication and adsorbent (Durrieu et al., 2004). The grafting APTES on HA surface is affected by major factors such as solvents, chemcial concentration, water content, reaction time, reaction temperature (Goonasekera, Jack, Cooper-White, \& Grøndahl, 2013). Therefore, the study focused on the grafting of APTES on HA surface and parameters influencing the process. The HA was synthesized from catfish bone according to the method mentioned by previous study (Ho, Tao, Huynh, \& Wang, 2020).

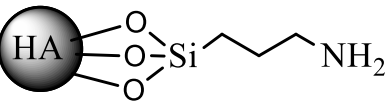

(SP1)
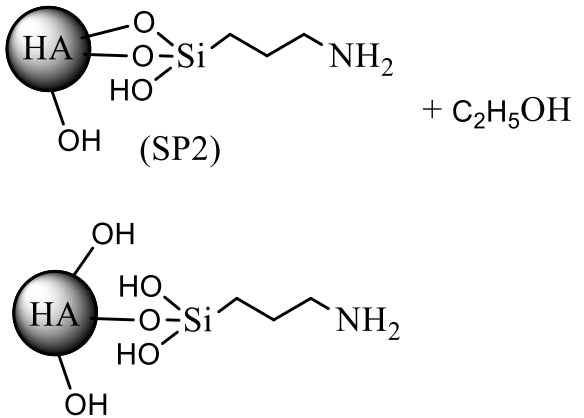

(SP3)

Figure 1. Grafting mechanism of APTES onto hydroxyapatite surface

cut into small pieces and subjected to $0.1 \mathrm{M} \mathrm{NaOH}$ solution for 24 hours. The treated bone was washed with distilled water and ethanol to remove remaining fats and other impurities, dried and calcined at $900^{\circ} \mathrm{C}$ for 6 hours in a furnace. The calcined bone was ground into powder with $5-10 \mu \mathrm{m}$ size range by high-speed ball mill. 10 grams of fish bone powder was then subjected to $60 \mathrm{mM} \mathrm{H}_{3} \mathrm{PO}_{4}$ aqueous solution with the ratio of $1 / 10(\mathrm{~g} / \mathrm{mL})$. Reaction was carried out at $90^{\circ} \mathrm{C}$, for 2 hours, at $\mathrm{pH} 11\left(\mathrm{NH}_{3}\right.$ was used to control solution $\mathrm{pH}$ ). After the reaction, the 
mixture was cooled to room temperature and aged for 24 hours before separating by vacuum filter. The sample was dried at $100^{\circ} \mathrm{C}$ and continuously calcined at $1000^{\circ} \mathrm{C}$ in 2 hours to stabilize the structure of HA product. X-ray diffraction (XRD) and scanning electron microscopy (SEM) were applied to characterize HA.

\subsection{Hydroxyapatite surface grafted APTES}

APTES was grafted onto the surface of HA surface to create amine functional groups based on the reaction mechanism described in Figure 1 (Da Silva et al., 2006). The incorporation of amine functional groups controlled the crystal dimensions and favours osteoblast proliferation, the activation of osteoblast metabolism and differentiation, which are all of high importance for potential biomedical applications. APTES was firstly hydrolysed in water to create silanol functional groups $\left[\mathrm{NH}_{2}-\right.$ $\left.\left(\mathrm{CH}_{2}\right)_{3} \mathrm{Si}(\mathrm{OH})_{3}\right]$. The silanol groups then reacted with the hydroxy groups $(\mathrm{OH})$ of HA to form chemical bonding and finally APTES grafted on HA surface. Typically, experiments was conducted following the procedure: HA was first dispersed in pure ethanol with the concentration of $1 / 25(\mathrm{~g} / \mathrm{mL})$ contained in bottle holder and applied in an ultrasonic bath for 5 minutes. The mixture was then stirred at $300 \mathrm{rpm}$ in a water bath. APTES and water was added to the suspension with different concentration. After the reaction, the mixture was vacuum filtered and subsequently washed 3 times with distilled water and ethanol to obtain HA grafted APTES. The sample was then dried at $60^{\circ} \mathrm{C}$ for 24 hours to obtain final product. Important factors affecting grafting reaction such as APTES concentration, water content, reaction temperature and reaction time were investigated
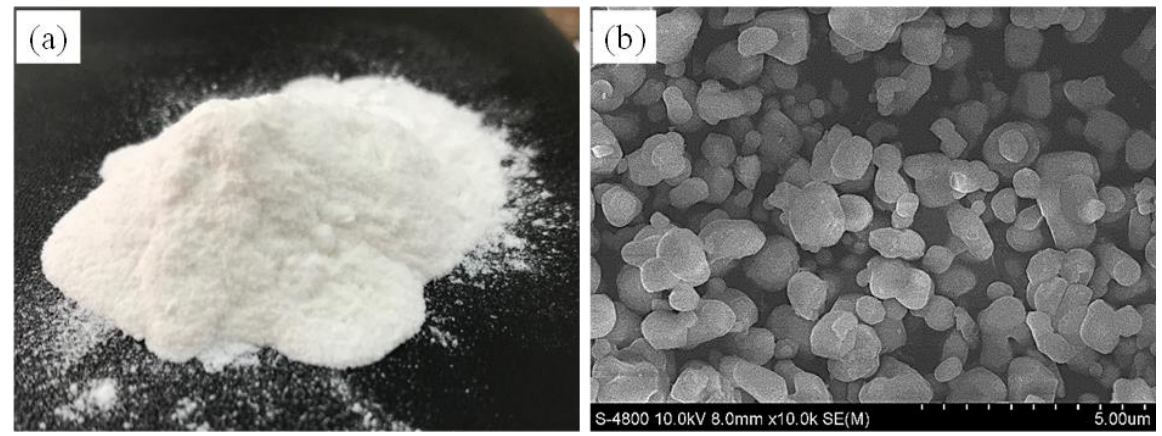

Figure 2. Hydroxyapatite powder prepared from catfish bone

(a) synthesized HA powder and (b) SEM image of synthesized HA powder. Reaction condition: Catfish powder/H $304=$ 1:10 g/mL, $\mathrm{H}_{3} \mathrm{PO}_{4}(60 \mathrm{mM}), \mathrm{pH} \mathrm{11,} \mathrm{reaction} \mathrm{temperature} 90^{\circ} \mathrm{C}$ and calcined temperature $1000^{\circ} \mathrm{C}$ for 2 hours 

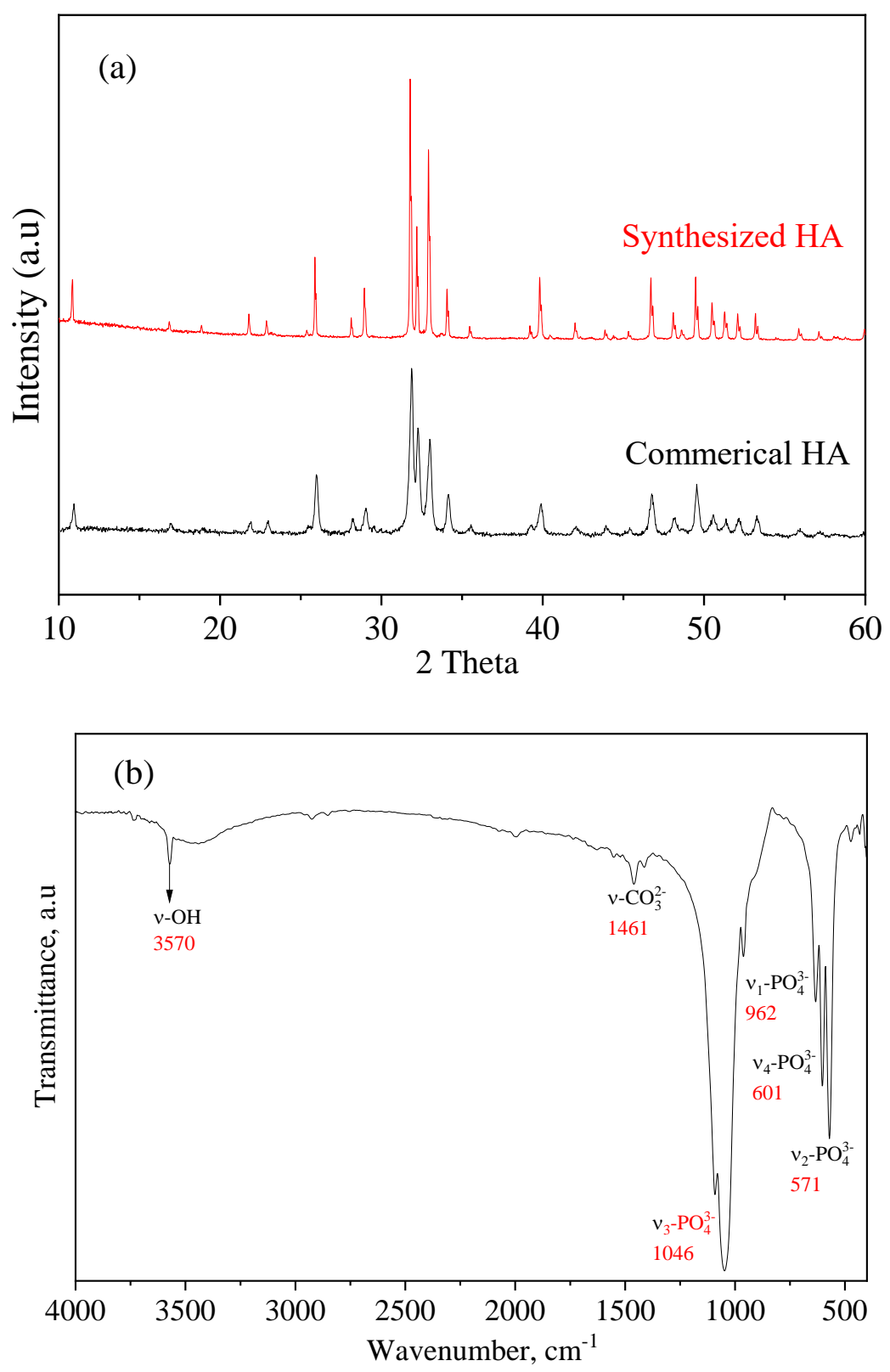

\section{Figure 3. Characterization of hydroxyapatite product prepared from catfish bone}

(a) XRD diffraction and (b) FT-IR spectrum. Reaction conditions: catfish powder $/ \mathrm{H}_{3} \mathrm{PO}_{4}=1: 10 \mathrm{~g} / \mathrm{mL}, \mathrm{H}_{3} \mathrm{PO}_{4}(60 \mathrm{mM})$, pH 11 , reaction temperature $90^{\circ} \mathrm{C}$ and calcine temperature $1000^{\circ} \mathrm{C}$ for 2 hours

\subsection{Effect of APTES concentration on grafting efficiency}

To investigate the effect of APTES concentration on grafting yield, different concentration of APTES was used. FT-IR spectra of HA sample showed characteristic absorption peaks of at $3570 \mathrm{~cm}^{-1}(\mathrm{v}-$ $\mathrm{H}-\mathrm{O}), 1046 \mathrm{~cm}^{-1}\left(v_{3}-\mathrm{PO}_{4}{ }^{3-}\right), 962 \mathrm{~cm}^{-1}\left(v_{1}-\mathrm{PO}_{4}{ }^{3-}\right)$, $601 \mathrm{~cm}^{-1}\left(v_{4}-\mathrm{PO}_{4}{ }^{3-}\right)$ and $571 \mathrm{~cm}^{-1}\left(v_{2}-\mathrm{PO}_{4}{ }^{3-}\right)$ which were correspondingly to $\mathrm{HO}^{-}$and $\mathrm{PO}_{4}{ }^{3-}$ of $\mathrm{HA}$ (Balasundaram, Sato, \& Webster, 2006; Liu et al., 2011; Motskin et al., 2009; Santos, Oliveira, Souza, Mansur, \& Vasconcelos, 2004; Wang et al., 2011) (Figure 3b). APTES grafting led to the presence of a new peak at $2929 \mathrm{~cm}^{-1}(\mathrm{v}-\mathrm{C}-\mathrm{H})$, $1465 \mathrm{~cm}^{-1}(\delta-\mathrm{C}-\mathrm{H}), 3400 \mathrm{~cm}^{-1}(v-\mathrm{N}-\mathrm{H}), 550 \mathrm{~cm}^{-1}$ $(\delta-\mathrm{N}-\mathrm{H})$, and $1410 \mathrm{~cm}^{-1}\left(v-\mathrm{Si}-\mathrm{CH}_{2}\right)$. Furthermore, 
there were also a peak at $471 \mathrm{~cm}^{-1}$ which was ascribed to the band of $\mathrm{v}$-Si-O-Si due to selfpolymerization of APTES (Figure 5) (Barakat, Khil, Omran, Sheikh, \& Kim, 2009; Howarter \& Youngblood, 2006). The peak located at $1465 \mathrm{~cm}^{-1}$ is known as the overlap between $(\delta-\mathrm{C}-\mathrm{H})$ and $(v-$ $\mathrm{CO}_{3}{ }^{2-}$ ) (Boerio, Armogan, \& Cheng, 1980; Chang \& Tanaka, 2002; Goonasekera et al., 2013) while absorption peak above $3700 \mathrm{~cm}^{-1}$ is assigned to stretching vibration of $\mathrm{SiO}-\mathrm{H}$ of polymer (Culler, Ishida, \& Koenig, 1985).

As expected, intensity of characteristic peaks between 1550 and $1410 \mathrm{~cm}^{-1}$ increased with an increasing APTES concentration. This suggested that the increase of APTES concentration provided better interaction between molecules, and therefore higher grafting efficiency on HA surface. This result had similar trends as grafting APTES on $\mathrm{TiO}_{2}$ surface (Song, Hildebrand, \& Schmuki, 2010; Zhang \& Srinivasan, 2004). Figure 4 also showed that as APTES concentration increased, the intensity of $\mathrm{Si}-\mathrm{O}-\mathrm{Si}$ group $\left(471 \mathrm{~cm}^{-1}\right)$ increased. The presence of new peaks compared to HA spectra confirmed that APTES was successfully grafted on HA surface. Highest absorption intensity of characteristic peaks was obtained at APTES 0.2 M.

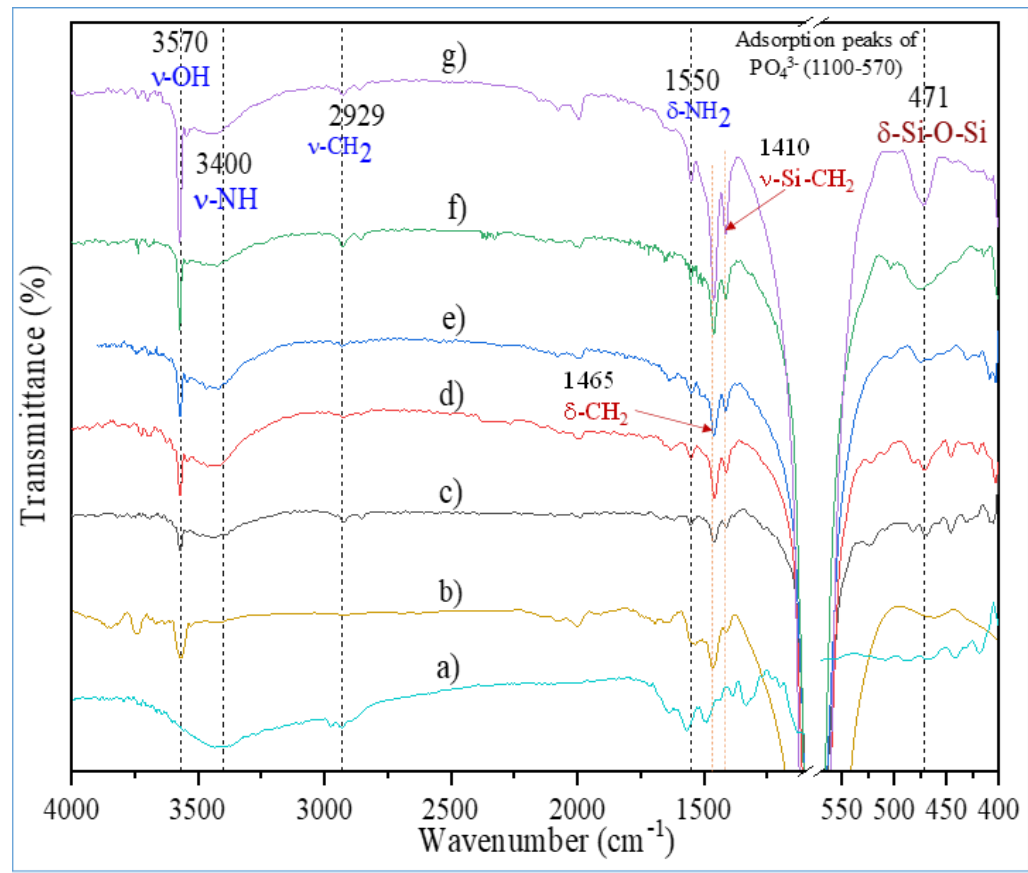

Figure 4. FT-IR spectra of (a) APTES, (b) HA from catfish bone, (c-g) has grafted APTES with different APTES concentration

(c) $0.01 \mathrm{M},(d) 0.05 \mathrm{M},(e) 0.1 \mathrm{M},(f) 0.15 \mathrm{M}$ and $(\mathrm{g}) 0.2 \mathrm{M}$.

All experiments were fixed at HAlethanol ratio $1: 25(w / v), 40{ }^{\circ} \mathrm{C}, 0.75 \mathrm{wt} \%$ water content for 4 hours.

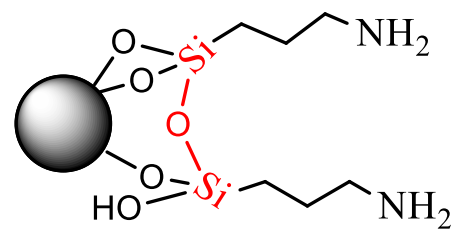

Figure 5. The formation of Si-O-Si bond

\subsection{Effect of water content on grafting efficiency}

Water took an important role in the hydrolysis of ethoxy groups of APTES molecules to form silanol groups to react with the $\mathrm{OH}$ group on HA surface (Pasternack et al., 2008). To investigate the effect of water content, experiments were conducted in different water content varied from $0 \mathrm{wt} . \%$ to 1.5 wt.\%. Experiment condition was controlled at $\mathrm{HA}$ /ethanol ratio $1: 25(\mathrm{w} / \mathrm{v}), 40^{\circ} \mathrm{C}, 0.2 \mathrm{M}$ APTES for 4 hours. Typical peaks characterized for HA and APTES were also obtained in FTIR spectra (Figure 6c-g). It was also notified that intensities of these peaks changed remarkably when the water content was changed. The intensity of $\mathrm{NH}_{2}$ increased as a function of water content and reach a 
maximum at 0.75 wt. $\%$ water content. The results agreed with the fact that more water would accelerate the hydrolysis of APTES ethoxy group, allowing the resulting hydroxysilane to attach on the HA surface (Engelhardt \& Orth, 1987; Howarter \& Youngblood, 2006). However, when the water content was higher than $0.75 \mathrm{wt} \%$, self polymerization of APTES (Figure 7a) was preferred leading to the formation of coating layer on HA rather than grafting (Damia, Sarda, Deydier, \& Sharrock, 2006; Song et al., 2010; Zhang \& Srinivasan, 2004). In the absence of water, grafting of APTES would be occurred between hydroxyl group of HA and amine group of APTES, therefore, no amine groups could be formed on HA surface (Figure 6b) (Song et al., 2010; Zhang \& Srinivasan, 2004).

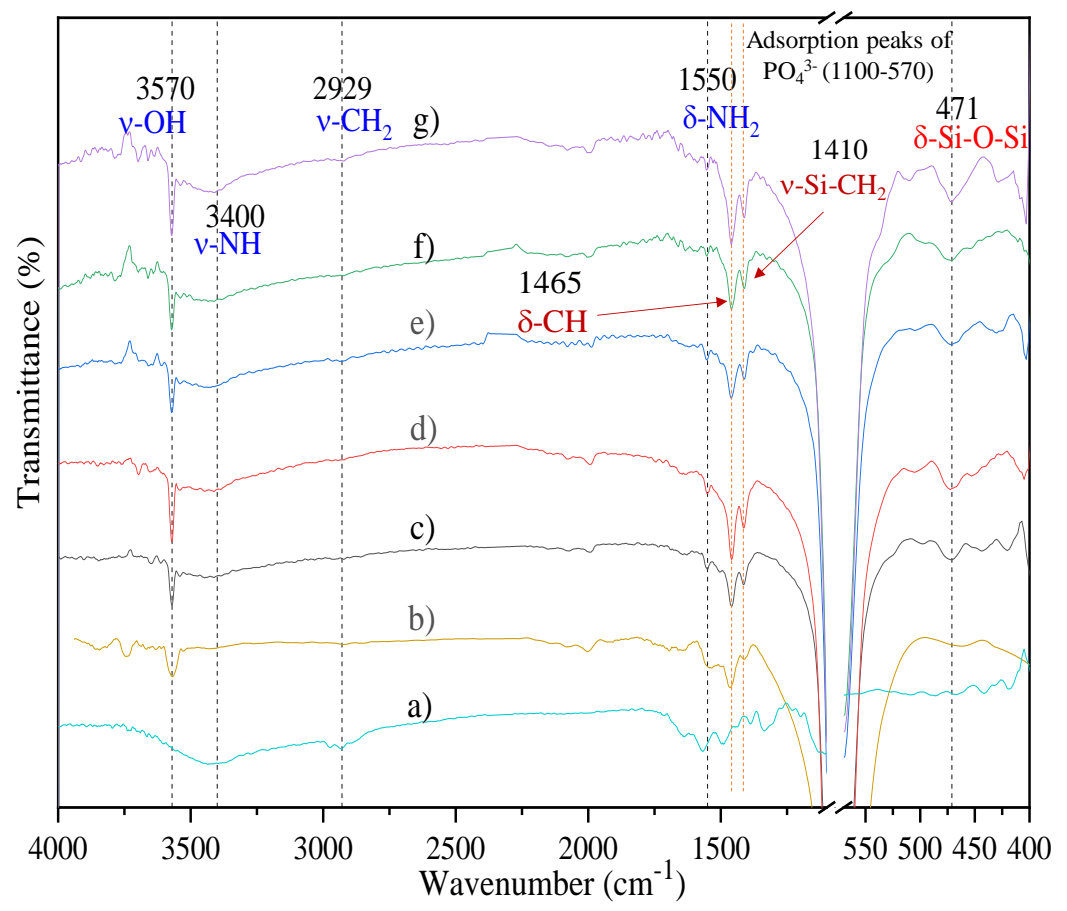

Figure 6. FT-IR spectra of (a) APTES standard, (b) HA from catfish bone, HA-APTES samples, prepared with different water content: (c) $0.5 \%$, (d) $0.75 \%$, (e) $0.1 \%$, (f) $1.25 \%$ and (g) $1.5 \%$

Experiment conditions: HA/ethanol ratio 1:25 (w/v), $40^{\circ} \mathrm{C}$, APTES 0.2 M, 4 hours.

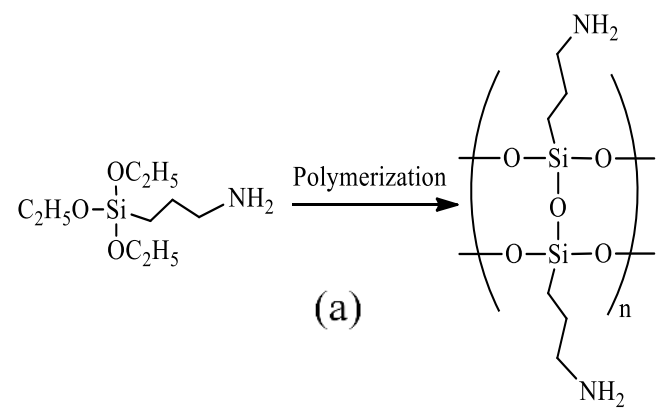<smiles>CCO[Si](O)(CCCN)O[Si](O)(CCCN)O[C@H]1CC[C@@H](O[NH2+]CCC[Si](O)(O)O)CC1O</smiles>

(b)

Figure 7. Formation of ionic bonds between amine group of APTES and hydroxyl group of HA (a) and polymerization of APTES to form a coating layer on HA surface (b) 


\subsection{Effect of reaction temperature on grafting efficiency}

To investigate the effect of temperature on grafting efficiency, experiments were conducted at different temperature ranged from $30^{\circ} \mathrm{C}$ to $70^{\circ} \mathrm{C}$ with HA/ethanol ratio $1: 25(\mathrm{w} / \mathrm{v})$, water content $0.75 \%$, APTES $0.2 \mathrm{M}$ for 4 hours. FTIR analysis confirmed the grafting of APTES on HA surface with characteristic peaks of HA at $3570 \mathrm{~cm}^{-1}, 1046 \mathrm{~cm}^{-1}$, $962 \mathrm{~cm}^{-1}, 601 \mathrm{~cm}^{-1}$ and $571 \mathrm{~cm}^{-1}$ as well as for APTES at $3400 \mathrm{~cm}^{-1}, 2929 \mathrm{~cm}^{-1}, 1465 \mathrm{~cm}^{-}, 550$ $\mathrm{cm}^{-1}$ and $1410 \mathrm{~cm}^{-1}$ (Figure $8 \mathrm{c}-\mathrm{g}$ ). The intensity of absorption peaks at $1550 \mathrm{~cm}^{-1}\left(\mathrm{NH}_{2}\right), 2929 \mathrm{~cm}^{-}$ ${ }^{1}\left(\mathrm{CH}_{2}\right)$ and $3570 \mathrm{~cm}^{-1}(\mathrm{v}-\mathrm{SiO}-\mathrm{H})$ increased with increasing temperature. This suggested that grafting efficiency increased with the increase of temperature. The highest intensity was obtained at reaction temperature of $70^{\circ} \mathrm{C}$. However, higher temperature led to a reduction in peak intensity $(\mathrm{v}-\mathrm{SiO}-$ $\mathrm{H})$ at $471 \mathrm{~cm}^{-1}$ (Figure $8 \mathrm{~g}$ ). This phenomenon can be explained by collision theory that raising the reaction temperature would bring more collisions, hence increase reaction rate i.e. grafting efficiency of APTES on HA. This result is entirely consistent with the study of Pasternack et al. (Pasternack et al., 2008). In addition, it was recommended that grafting temperature should not exceed $70^{\circ} \mathrm{C}$ since it is close to the boiling point of ethanol $\left(78^{\circ} \mathrm{C}\right)$.

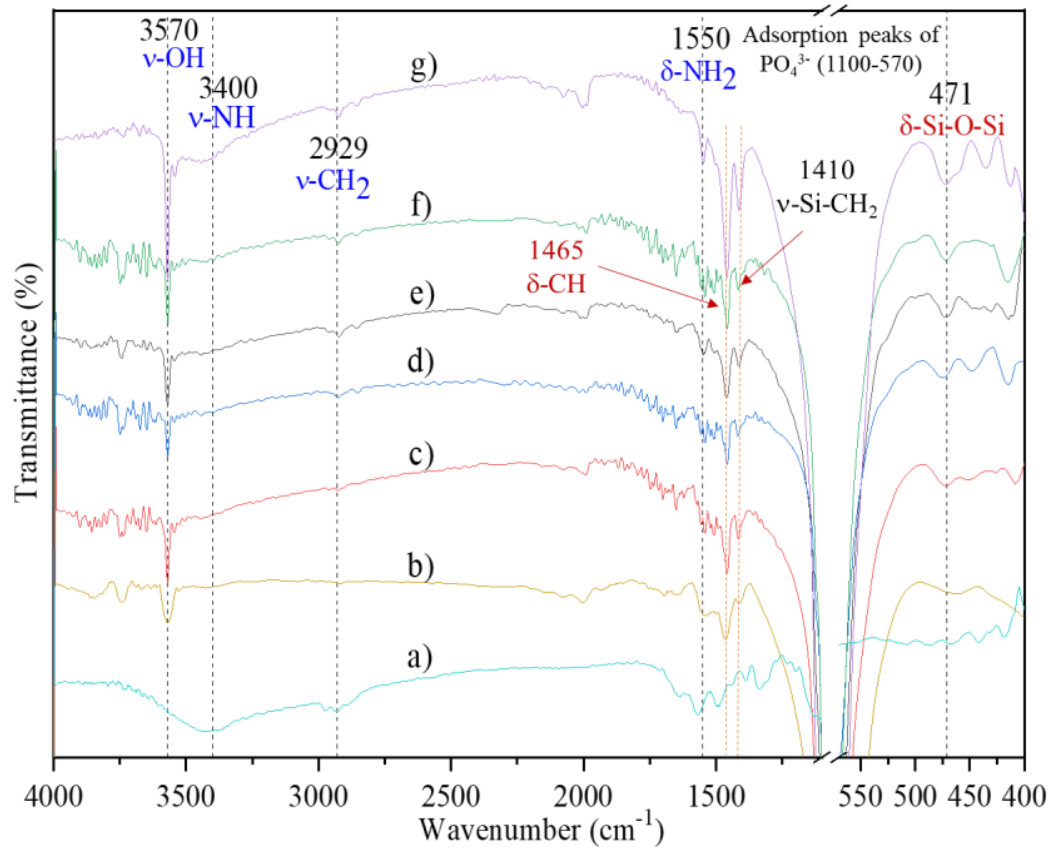

Figure 8. FT-IR spectra of (a) APTES standard, (b) HA from catfish bone, HA - APTES samples, prepared at different temperature: (c) $30^{\circ} \mathrm{C}$, (d) $40^{\circ} \mathrm{C}$, (e) $50^{\circ} \mathrm{C}$, (f) $60^{\circ} \mathrm{C}$ and (g) $70^{\circ} \mathrm{C}$

Experiment conditions: HA/ethanol ratio 1:25 (w/v), APTES $0.2 \mathrm{M}, 0.75$ wt. \% water content for 4 hours.

\subsection{Effect of reaction time on grafting efficiency}

To understand the effect of reaction time on grafting efficiency, the experiments were conducted at different intervals of time from 2 to 24 hours. All experiments were performed at HA/ethanol ratio 1:25 (w/v), water content $0.75 \%$, APTES $0.2 \mathrm{M}$, and reaction temperature $70^{\circ} \mathrm{C}$. Typical absorption peaks of HA and APTES were identified in FTIR spectra (Figure 9). Data obtained also showed that the intensity of absorption peaks increased with increasing reaction time. Especially, there was a sharp increment in the intensity of $-\mathrm{NH}_{2}$ peak at 12 hours. However, intensity of characteristic absorption peaks is no different when reaction time is raised to 24 hours. It can be clearly understood that prolong reaction time would increase $\mathrm{NH}_{2}-\left(\mathrm{CH}_{2}\right)_{3} \mathrm{Si}(\mathrm{OH})_{3}$ concentration, increase the formation of HA-O-Si bond, therefore increasing grafting efficiency. However, longer reaction time could also cause self-reaction of silanol groups $(\mathrm{Si}-\mathrm{OH})$ to form $\mathrm{Si}-$ $\mathrm{O}-\mathrm{Si}$ bonding or self-polymerization of APTES, resulting in a covered film on HA surface. These observations were confirmed by the increase in absorption intensity at $471 \mathrm{~cm}^{-1}$ (Song et al., 2010) 
as well as SEM images of HA-APTES samples (Figure 9). No significant difference between the surface of pristine HA and HA-APTES grafting in 2 hours was found (Figure 10a and 10b) while there was a covered layer of APTES on HA surface accompanied by an increment in HA particle size after 24 hours grafting (Figure 10c).

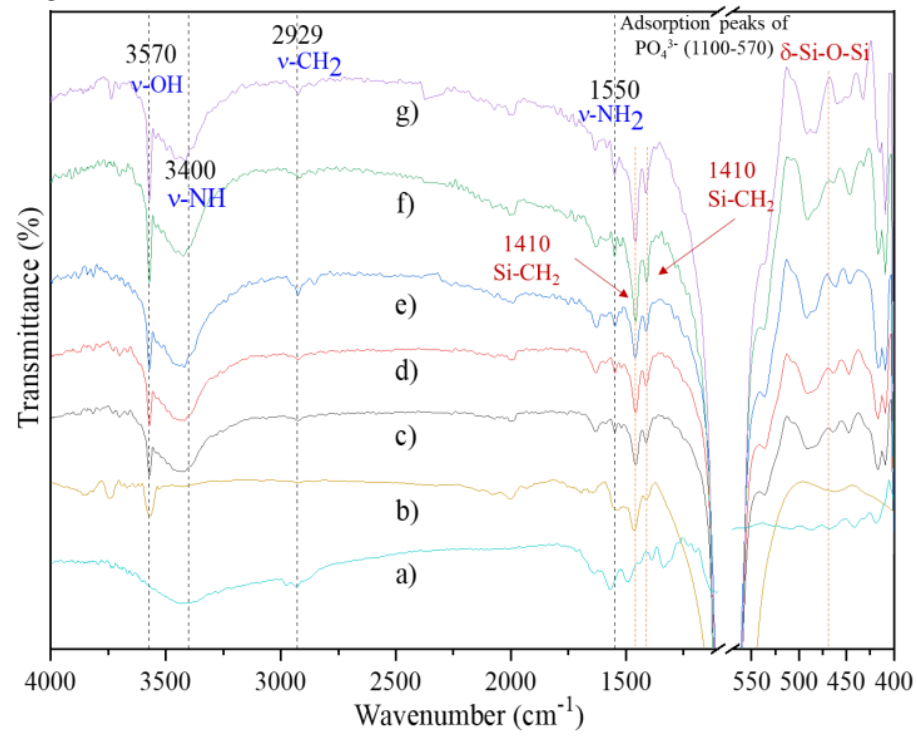

Figure 9. FT-IR spectra of (a) APTES standard, (b) HA from catfish bone

HA - APTES samples were prepared with different time: (c) $2 h,(d) 4 h,(e) 8 h,(f) 12 h$ and $(g) 24 h$. Experiment conditions: HA/ethanol ratio 1:25 (w/v), APTES $0.2 \mathrm{M}, 0.75 \mathrm{wt} . \%$ water content.
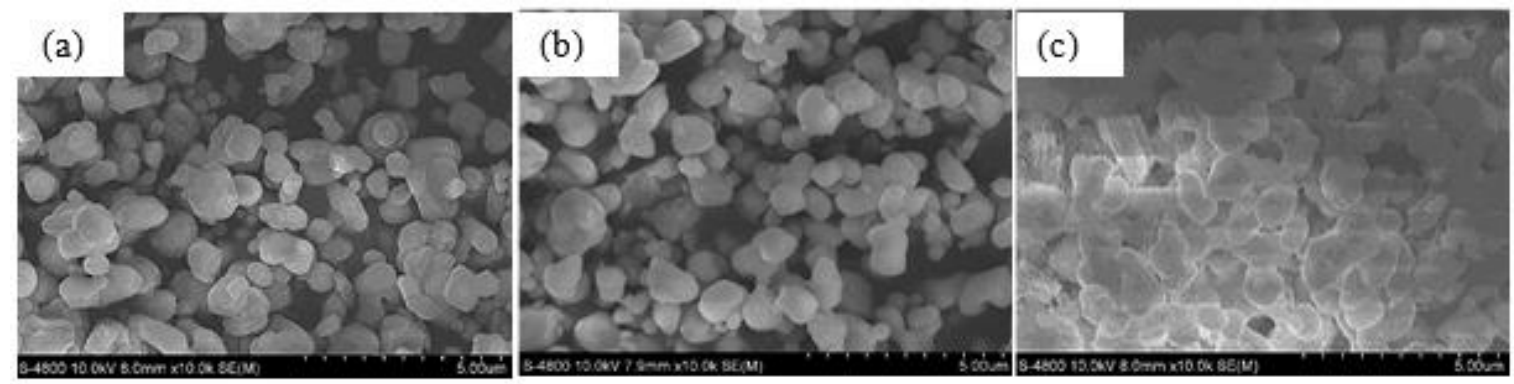

Figure 10. SEM images of (a) HA from catfish bone; (b) HA-APTES samples were prepared at 2 hours and (c) 24 hours

Experiment conditions: HA/ethanol ratio $1: 25(w / v)$, water content $0.75 \%$, APTES $0.2 \mathrm{M}$, reaction temperature $70{ }^{\circ} \mathrm{C}$.

\section{CONCLUSION}

Hydroxyapatite particles with size around 1000 $\mathrm{nm}$ were succesfully prepared from catfish bones treated with $60 \mathrm{mM} \mathrm{H}_{3} \mathrm{PO}_{4}$ solution, at a catfish powder/ $\mathrm{H}_{3} \mathrm{PO} 4$ of $1: 10 \mathrm{~g} / \mathrm{mL}, \mathrm{pH} 11$ and $90^{\circ} \mathrm{C}$ followed by calcination at $1000^{\circ} \mathrm{C}$ for 2 hours. Incorporation of amine functional groups into HA particles was determined by grafting efficiency of APTES to HA surface. Experimental results showed that APTES was successfully grafted on HA under reaction condition of $0.2 \mathrm{M}$ APTES solution, 0.75 wt. $\%$ water content, at $70{ }^{\circ} \mathrm{C}$ for 12 hours.

\section{ACKNOWLEDGMENT}

This study is funded in part by the Can Tho University Improvement Project VN14-P6, supported by a Japanese ODA loan (Grant No.:F4-4).

\section{REFERENCES}

Balasundaram, G., Sato, M., \& Webster, T. J. (2006). Using hydroxyapatite nanoparticles and decreased crystallinity to promote osteoblast adhesion similar to functionalizing with RGD. Biomaterials, 27(14), 2798-2805.

Barakat, N. A., Khil, M. S., Omran, A., Sheikh, F. A., \& Kim, H. Y. (2009). Extraction of pure natural hy- 
droxyapatite from the bovine bones bio waste by three different methods. Journal of materials processing technology, 209(7), 3408-3415.

Boerio, F., Armogan, L., \& Cheng, S. (1980). The structure of $\gamma$-aminopropyltriethoxysilane films on iron mirrors. Journal of Colloid Interface Science, 73(2), 416-424.

Chang, M. C., \& Tanaka, J. (2002). FT-IR study for hydroxyapatite/collagen nanocomposite cross-linked by glutaraldehyde. Biomaterials, 23(24), 4811-4818.

Culler, S., Ishida, H., \& Koenig, J. (1985). Structure of silane coupling agents adsorbed on silicon powder. Journal of colloid and interface science, 106(2), 334-346.

Da Silva, O. G., Da Silva Filho, E. C., Da Fonseca, M. G., Arakaki, L. N., \& Airoldi, C. (2006). Hydroxyapatite organofunctionalized with silylating agents to heavy cation removal. J Colloid Interface Sci, 302(2), 485-491.

Damia, C., Sarda, S., Deydier, E., \& Sharrock, P. (2006). Study of two hydroxyapatite/poly (alkoxysilane) implant coatings. Surface Coatings Technology, 201(6), 3008-3015.

Durrieu, M. C., Pallu, S., Guillemot, F., Bareille, R., Amedee, J., Baquey, C. H., . . . \& Dard, M. (2004). Grafting RGD containing peptides onto hydroxyapatite to promote osteoblastic cells adhesion. J Mater Sci Mater Med, 15(7), 779-786.

Engelhardt, H., \& Orth, P. (1987). Alkoxy silanes for the preparation of silica based stationary phases with bonded polar functional groups. Journal of liquid chromatography, 10(8-9), 1999-2022.

Goonasekera, C. S., Jack, K. S., Cooper-White, J. J., \& Grøndahl, L. (2013). Attachment of poly (acrylic acid) to 3-aminopropyltriethoxysilane surface-modified hydroxyapatite. Journal of Materials Chemistry B, 1(42), 5842-5852.

Haixin Zhao, Wenjun Dong, Yingying Zheng, Aiping Liu, Juming Yao, Chaorong Li, ... Shi, Z. (2011). The structural and biological properties of hydroxyapatite-modified titanate nanowire scaffolds. Biomaterials, 32(25), 5837-5846.

Ho, Q.-P., Tao, T.-D., Huynh, L.-H., \& Wang, M.-J. (2020). Biocomposite scaffold preparation from hydroxyapatite extracted from waste bovine bone. Green Processing and Synthesis, 9(1), 37-47.

Howarter, J. A., \& Youngblood, J. P. (2006). Optimization of silica silanization by 3 aminopropyltriethoxysilane. Langmuir, 22(26), 11142-11147. doi:10.1021/la061240g
Kim, H. W., Lee, H. H., \& Knowles, J. (2006). Electrospinning biomedical nanocomposite fibers of hydroxyapatite/poly (lactic acid) for bone regeneration. Journal of Biomedical Materials research. Part A, 79(3), 643-649.

Liu, H., Chen, F., Xi, P., Chen, B., Huang, L., Cheng, J., ... Zeng, Z. (2011). Biocompatible fluorescent hydroxyapatite: synthesis and live cell imaging applications. The Journal of Physical Chemistry C, 115(38), 18538-18544.

Motskin, M., Wright, D. M., Muller, K., Kyle, N., Gard, T. G., Porter, A. E., \& Skepper, J. N. (2009). Hydroxyapatite nano and microparticles: correlation of particle properties with cytotoxicity and biostability. Biomaterials, 30(19), 3307-3317.

Pasternack, R. M., Rivillon Amy, S., \& Chabal, Y. J. (2008). Attachment of 3-(aminopropyl) triethoxysilane on silicon oxide surfaces: dependence on solution temperature. Langmuir, 24(22), 12963-12971.

Rivera-Muñoz, \& M, E. (2011). Hydroxyapatite-based materials: synthesis and characterization: IntechOpen.

Sadat-Shojai, M., Khorasani, M.-T., DinpanahKhoshdargi, E., \& Jamshidi, A. (2013). Synthesis methods for nanosized hydroxyapatite with diverse structures. Acta biomaterialia, 9(8), 7591-7621.

Santos, M. H., Oliveira, M. d., Souza, L. P. d. F., Mansur, H. S., \& Vasconcelos, W. L. (2004). Synthesis control and characterization of hydroxyapatite prepared by wet precipitation process. Materials Research, 7(4), 625-630.

Song, Y.-Y., Hildebrand, H., \& Schmuki, P. (2010). Optimized monolayer grafting of 3aminopropyltriethoxysilane onto amorphous, anatase and rutile TiO2. Surface Science, 604(3-4), 346-353.

Wang, S., Wen, S., Shen, M., Guo, R., Cao, X., Wang, J., \& Shi, X. (2011). Aminopropyltriethoxysilanemediated surface functionalization of hydroxyapatite nanoparticles: synthesis, characterization, and in vitro toxicity assay. International journal of nanomedicine, 6, 3449.

Ylinen, P. (2006). Applications of coralline hydroxyapatite with bioabsorbable containment and reinforcement as bone graft substitute. University of Helsinki, Helsinki, Finland.

Zhang, F., \& Srinivasan, M. (2004). Self-assembled molecular films of aminosilanes and their immobilization capacities. Langmuir, 20(6), 2309-2314. 